\title{
Aspirin Resistance in Acute Ischemic Non-cardioembolic Stroke: Frequency and Clinical Study
}

\author{
Yosria Abd -Al Hameed Altaweel, Amr Elsayed Kamel, Sabah Mohammad Lotfy, \\ Nancy Abd-Al Hameed Mohammad* \\ Neurology Department, Zagazig University, Egypt \\ *Corresponding author: nancyabdelhamid@yahoo.com
}

\begin{abstract}
Platelet activation in cerebrovascular diseases is associated with recurrent stroke and death. Aspirin is an effective antiplatelet agent, exhibiting its action by irreversibly inhibiting platelet cyclooxygenase- 1 enzyme, thus preventing the production of thromboxane $\mathrm{A}_{2}\left(\mathrm{TXA}_{2}\right)$. Objectives: The study is designed to find the frequency of aspirin resistance (AR) among acute ischemic non-cardioembolic stroke patients, and to assess the clinical picture of those patients. Mehtods: This study included 80 patients39 males and 41 females (mean age: 63 years $\pm 11.8 \mathrm{SD}$ ), they were diagnosed clinically and via brain imaging within 24 hours following stroke onset. They were given non coated, same preparation of aspirin $150 \mathrm{mg} /$ day regularly and under observation, Low molecular weight heparin 40 mg per day. The patients were followed up clinically and via GCS, NIHSS and APACHEII scales. Assessment of aspirin resistance was done one week after regular aspirin intake through: bleeding time, coagulation time and assessment of thromboxaneA2 level in serum using ELIZA. The patients were classified into two groups aspirin resistant (AR) and aspirin sensitive (AS) and the data were compared in both. Results: AR patients represented $33.75 \%$ of our sample. History of TIAs and stroke was more prevalent among them. In AR patients: the followings were also more frequent: more affection of consciousness, power, sensation, language, coordination, vertigo, vomiting, large size of cerebral infarcts, temporal and parietal infarcts. There were high significant negative correlation between GCS and TXA2level and between the later and changes in bleeding time in the first day and 7 days following stroke onset. On the other hand there were high positive correlation between TXA2 level and NIHSS score and infarct size. Coclusion: AR was frequent among ischemic non-cardioembolic stroke and they were associated with history of TIAs and previous strokes, and presented with more severe clinical presentation and larger size of cerebral infarcts, So early identification of AR prevents its fruitless use.
\end{abstract}

Keywords: ischemic stroke, aspirin resistance, platelets

Cite This Article: Yosria Abd -Al Hameed Altaweel, Amr Elsayed Kamel, Sabah Mohammad Lotfy, and Nancy Abd-Al Hameed Mohammad, "Aspirin Resistance in Acute Ischemic Non-cardioembolic Stroke: Frequency and Clinical Study." International Journal of Clinical and Experimental Neurology, vol. 5, no. 1 (2017): 33-37. doi: 10.12691/ijcen-5-1-7.

\section{Introduction}

Arterioarterial microthromboembolism is an important factor in the pathogenesis of ischemic stroke. Platelet activation in cerebrovascular diseases is associated with recurrent stroke and death, and the inhibition of platelet function by antiplatelet drugs including aspirin lowers the risk of ischemic stroke [1].

$\mathrm{TXA}_{2}$ is a potent platelet agonist that, through stimulation of $\mathrm{G}$ protein-coupled receptors on platelets, brings about platelet aggregation and thrombus formation. Although other factors have roles in platelet aggregation and thrombus formation, evidence shows that $\mathrm{TXA}_{2}$ is an essential contributor. $\mathrm{TXA}_{2}$ production is an early event platelet activation and potentiates other mediators with proaggregative effects. Platelet-derived $\mathrm{TXA}_{2}$ also diffuses to subendothelial vascular smooth muscle, where it induces smooth muscle contraction and vasoconstriction.
Because vasoconstriction might enhance thrombus formation, aspirin inhibition of this step might further augment its therapeutic efficacy [2].

$\mathrm{AR}$ is the inability of aspirin to reduce the platelet production of thromboxane $A_{2}$, and thereby platelet aggregation and activation [3].

The mechanism of AR is uncertain uptill now resistance is common in female and elderly [4] Several pharmacodynamic and pharmacokinetic factors are likely to play a role in the variability of platelet inhibition, including bioavailability, patient compliance, genetic polymorphisms, activation of alternate platelet-stimulation pathways, accelerated platelet turnover, co-morbid risk factors such as hypercholesterolaemia, diabetes mellitus, smoking and renal diseases [5]. By-pass surgery for coronary artery obstruction, long term use of aspirin, type of aspirin preparation and drug interaction (like with statins, non-steroidal anti inflammatory drugs, proton pump inhibitors) are also other mechanisms of AR [6]. 


\section{Patients and Methods}

This study was conducted in Intensive Care Unit and Stroke Unit of Neurology Department, Zagazig University Hospitals during the period from January 2014 to March 2017. The study included 80 patients 39 males and 41 females (mean age: 63 years $\pm 11.8 \mathrm{SD}$ ). The patients with acute ischemic non-cardioembolic stroke either first or recurrent stroke were choosen consequetivly within the $1^{\text {st }}$ 24 hours of stroke onset.

The diagnosis was confirmed clinically, via echocardiography and radiologically via brain imaging with CT and /or MRI brain which was:either free, or with early radiological signs of brain infarct in plain CT or with recent cerebral infarct. Another follow up brain imaging was done one week later. Also routine laboratory investigations and coagulation profile were done.

We excluded patients with transient ischemic attacks (TIAs) (neurological deficit lasting less than one hour with no evidence of recent infarct on brain imaging), hemorrahgic stroke, major cardiovascular event within the past 3 months and lor current AF, alcohol drinkers, the last trimester of pregnancy, Patients with tinnitus, those patients with absolute contraindications to aspirin as peptic ulcer, and stress ulcer, diseases interact with aspirin: coagulopathy, aneamia, bronchial asthma, dialysis, GIT toxicity, G6PD deficiency, renal dysfunction, hepatotoxicity, Reye's syndrome; patients with hyperuricemia or gout, platelet function disorders or bleeding diathesis. Allergy to ibuprofen or naproxen. Concurrent medication with additional antiplatelet (e.g. clopidogril, ticlopidine, cilostazole, dipiridamole, abciximab, and tirofiban); anti coagulant and nonsteroidal anti- inflammatory for the last 10 days, terminal diseases like liver failure, renal failure, respiratory failure, terminal cancer and life threatening infections.

All patients in our study received:

Non coated, same preparation of aspirin $150 \mathrm{mg} / \mathrm{day}$ regularly and under observation and low molecular weight heparin $40 \mathrm{mg}$ per day,
The patients were assessed clinically and via the following neurological scales Glasgow Coma Scale (GCS), National Institute of Health Stroke Scale (NIHSS) and Acute Physiologic and Chronic Health Evaluation (APACHE) on admission and one week later for survivors.

Assessment of AR was done one week after regular aspirin intake through: bleeding time, coagulation time and assessment of thromboxane $\mathrm{A} 2$ level in serum by using ELIZA.The The frequency of AR patients was assessed.

The clinical profile of both AS and AR patients were compared. The follow up results were investigated. Statistical analysis was done using SPSS version 22 [7].

\section{Results}

In this study we found that AR patients represented $33.75 \%$ of the studied survivors with acute ischemic noncardioembolic stroke. Level of consciousness was less disturbed in AS patients, stroke severity was higher in AR patients. There were significant differences between the two groups regarding degree of weakness, sensory loss, dysphasia, ataxia, vertigo, vomiting and disturbed consciosness. They were more prevalent in AR patients. History of transient ischemic attacks (TIAs) and previous stroke were significant among patients with AR.

Large size infarcts and temporal and parietal sites were more prevelant in AR patients with statistical significant difference than AS ones.

There was significantly high negative correlation between GCS and TXA2 level and there was also significantly high positive correlation between NIHSS and TXA2 level.

There was significantly negative correlation between change in bleeding time ( $1^{\text {st }}$ day \&after one week) and TXA2 level and highly significant positive correlation between size of infarction and TXA2 level.

Table 1. Frequency and Demographic characteristics of both groups of patient

\begin{tabular}{|c|c|c|c|c|c|c|}
\hline $\begin{array}{ll}\text { Data } & \text { Groups } \\
\end{array}$ & \multicolumn{2}{|c|}{$\begin{array}{l}\text { Aspirin resistant } \\
\mathrm{N}=27 \text { patients }\end{array}$} & \multicolumn{2}{|c|}{$\begin{array}{l}\text { Aspirin sensitive } \\
\mathrm{N}=53 \text { patients }\end{array}$} & t-test & $\mathrm{P}$ \\
\hline Age Range 30-90yrs & \multicolumn{2}{|c|}{ 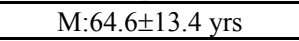 } & \multicolumn{2}{|c|}{$63.3 \pm 11.0$} & 0.48 & 0.63 \\
\hline Sex & $\%$ & No. & $\%$ & No. & $\mathrm{X}^{2}$ & $\mathrm{P}$ \\
\hline Male & 10 & 37.0 & 29 & 54.7 & \multirow{2}{*}{2.24} & \multirow{2}{*}{0.13} \\
\hline Female & 17 & 63.0 & 24 & 45.3 & & \\
\hline Frequency & 27 & 33.75 & 53 & 66.25 & & \\
\hline
\end{tabular}

Table 2. Risk Factors of stroke in both groups

\begin{tabular}{|c|c|c|c|c|c|c|}
\hline \multirow{2}{*}{$\mathrm{P}_{\text {Risk factors }}^{\text {Groups }}$} & \multicolumn{2}{|c|}{$\begin{array}{c}\text { Aspirin resistant } \\
\mathrm{N}=27\end{array}$} & \multicolumn{2}{|c|}{$\begin{array}{c}\text { Aspirin sensitive } \\
\mathrm{N}=53\end{array}$} & \multirow[t]{2}{*}{$X^{2}$} & \multirow[t]{2}{*}{$\mathrm{P}$} \\
\hline & No. & $\%$ & No. & $\%$ & & \\
\hline Age: $>55$ years & 19 & 70.4 & 39 & 73.6 & 0.09 & 0.76 \\
\hline \multicolumn{7}{|l|}{ Sex: } \\
\hline Male: & 10 & 37 & 29 & 54.7 & 2.24 & 0.13 \\
\hline Female: & 17 & 63 & 24 & 45.3 & & \\
\hline Smoking & 10 & 37.0 & 25 & 47.2 & 0.75 & 0.38 \\
\hline Diabetes & 14 & 51.9 & 26 & 49.1 & 0.06 & 0.81 \\
\hline Hypertension & 18 & 66.7 & 39 & 73.6 & 0.42 & 0.51 \\
\hline Dyslipidemia & 13 & 48.1 & 25 & 47.2 & 0.01 & 0.93 \\
\hline Previous ischemic stroke & 10 & $37 \%$ & 7 & $13.2 \%$ & 6.07 & $0.013 *$ \\
\hline TIAs & 2 & 7.4 & 0 & 0.0 & 3.98 & $0.04 *$ \\
\hline Migraine & 5 & 18.5 & 9 & 17.0 & 0.02 & 0.89 \\
\hline Obesity & 14 & 51.9 & 19 & 35.8 & 1.89 & 0.16 \\
\hline Obstructive sleep apnea & 4 & 14.8 & 2 & 3.8 & 1.75 & 0.18 \\
\hline Oral contraceptive pills & $3 / 17$ & 17.6 & $2 / 24$ & 8.3 & 0.83 & 0.36 \\
\hline
\end{tabular}


Table 3. Clinical presentation in both group

\begin{tabular}{|c|c|c|c|c|c|c|}
\hline $\begin{array}{ll}\text { Presentations } & \text { Groups } \\
\end{array}$ & \multicolumn{2}{|c|}{$\begin{array}{l}\text { Aspirin resistant } \\
(\mathrm{N}=27)\end{array}$} & \multicolumn{2}{|c|}{$\begin{array}{l}\text { Aspirin sensitive } \\
(\mathrm{N}=53)\end{array}$} & $\mathrm{X}^{2}$ & $\mathrm{P}$ \\
\hline Disturbed consciousness & 11 & 40.7 & 3 & 5.7 & 12.91 & $0.001 *$ \\
\hline Gaze palsies & 13 & 48.1 & 14 & 26.4 & 0.26 & 0.61 \\
\hline Visual field defect & 9 & 33. & 13 & 24.5 & 0.7 & 0.4 \\
\hline Cranial nerves & 21 & 77.8 & 30 & 56.6 & 3.47 & 0.06 \\
\hline Dysphasia: & $15 / 27$ & 55.7 & $17 / 53$ & 32 & 4.11 & $<0.04 *$ \\
\hline Motor & 4 & 14.8 & 5 & 9.4 & 0.12 & 0.72 \\
\hline Sensory & 7 & 25.95 & 6 & 11.3 & 1.83 & 0.17 \\
\hline Global & 4 & 14.8 & 6 & 11.3 & 0.01 & 0.92 \\
\hline Dysarthria & 21 & 77.8 & 45 & 84.9 & 0.63 & 0.42 \\
\hline Apraxia & 10 & 37 & 16 & 30.2 & 0.38 & 0.53 \\
\hline Extinction\&inattention & 8 & 29.6 & 16 & 30.2 & 0.0 & 0.95 \\
\hline $\begin{array}{l}\text { Degree of weakness } \\
\text {-paralysis } \\
\text {-Paresis }\end{array}$ & $\begin{array}{l}16 \\
10\end{array}$ & $\begin{array}{c}59.2 \\
37\end{array}$ & $\begin{array}{l}14 \\
39\end{array}$ & $\begin{array}{l}26.4 \\
73.5\end{array}$ & 9.14 & $0.002 *$ \\
\hline $\begin{array}{l}\text { Sensory symptoms: } \\
\text { Hyposthesia } \\
\text { Anaesthesia }\end{array}$ & $\begin{array}{c}5 \\
18\end{array}$ & $\begin{array}{l}18.5 \\
66.6\end{array}$ & $\begin{array}{l}26 \\
13\end{array}$ & $\begin{array}{c}49 \\
24.5\end{array}$ & 11.68 & $<0.001 *$ \\
\hline Ataxia & 4 & 14.8 & 1 & 1.9 & 5.04 & $0.02 *$ \\
\hline Dizziness & 8 & 29.6 & 13 & 24.5 & 0.24 & 0.62 \\
\hline Vertigo & 5 & 18.5 & 2 & 3.8 & 4.81 & $0.02 *$ \\
\hline Vomitting & 10 & 37.0 & 6 & 11.3 & 7.39 & $0.006 *$ \\
\hline
\end{tabular}

Table 4. GCS, NIHSS and APACHE II (within 24 hours of stroke onset).

\begin{tabular}{|c|c|c|c|c|}
\hline Scale $\quad$ Groups & $\begin{array}{c}\text { Aspirin resistant } \\
\mathrm{N}=27\end{array}$ & $\begin{array}{c}\text { Aspirin sensitive } \\
\mathrm{N}=53\end{array}$ & $\mathrm{t}$-test & $\mathrm{P}$ \\
\hline $\begin{array}{l}\mathrm{GCS} \pm \mathrm{SD} \\
\text { Range }\end{array}$ & $\begin{array}{c}11.26 \pm 2.6 \\
7-15\end{array}$ & $\begin{array}{c}13.5 \pm 2.2 \\
6-15\end{array}$ & 4.1 & $<0.001 * *$ \\
\hline $\begin{array}{l}\text { NIHSS } \pm \text { SD } \\
\text { Range }\end{array}$ & $\begin{array}{c}17.7 \pm 5.9 \\
6-28\end{array}$ & $\begin{array}{c}10.2 \pm 5.1 \\
2-20\end{array}$ & 5.8 & $<0.001 * *$ \\
\hline $\begin{array}{l}\text { APACHE II } \pm \text { SD } \\
\text { Range }\end{array}$ & $\begin{array}{l}14.1 \pm 9.0 \\
4 \%-40 \%\end{array}$ & $\begin{array}{c}8.1 \pm 4.2 \\
4 \%-25 \%\end{array}$ & 4.03 & $<0.001 * *$ \\
\hline
\end{tabular}

Table 5. GCS, NIHSS and APACHE II (one week after stroke onset)

\begin{tabular}{|l|c|c|c|c|}
\hline \multirow{2}{*}{ Scales } & Aspirin resistant & Aspirin sensitive & t-test & P \\
\hline \multirow{2}{*}{ GCS } & $11.3 \pm 2.6$ & $\begin{array}{c}13.4 \pm 2.2 \\
6-15\end{array}$ & 3.94 & $<0.001 * *$ \\
\hline \multirow{2}{*}{ NIHSS } & $7-15$ & $\begin{array}{c}9.2 \pm 4.4 \\
1-17\end{array}$ & 6.89 & $<0.001 * *$ \\
\hline \multirow{2}{*}{ APACHE II } & $17.2 \pm 5.9$ & $\begin{array}{c}6.5 \pm 3.2 \\
4 \%-25 \%\end{array}$ & 4.8 & $<0.001 * *$ \\
\hline
\end{tabular}

Table 6. Size of infarct in both groups

\begin{tabular}{|c|c|c|c|c|c|c|}
\hline Size $\quad$ Groups & \multicolumn{2}{|c|}{$\begin{array}{c}\text { Aspirin resistant } \\
\mathrm{N}=27\end{array}$} & \multicolumn{2}{|c|}{$\begin{array}{c}\text { Aspirin sensitive } \\
\mathrm{N}=53\end{array}$} & \multirow{2}{*}{$\begin{array}{c}X \\
9.04\end{array}$} & \multirow{2}{*}{$\frac{\mathrm{P}}{0.002 *}$} \\
\hline Lacunar $<1.5 \mathrm{~cm}$ & 1 & $3.7 \%$ & 18 & $34.0 \%$ & & \\
\hline Small $1.5-3 \mathrm{~cm}$ & 4 & $14.8 \%$ & 7 & $13.2 \%$ & 0.02 & 0.88 \\
\hline Medium 3-5 cm & 1 & $3.7 \%$ & 14 & $26.4 \%$ & 6.06 & $0.013 *$ \\
\hline Large $>5 \mathrm{~cm}$ & 21 & $77.8 \%$ & 14 & $26.4 \%$ & 19.18 & $<0.001 * *$ \\
\hline Watershed infarct & & & & & --- & --- \\
\hline
\end{tabular}

Table 7. Correlation between TXA2 and GCS, NIHSS and APACHII scales in both groups

\begin{tabular}{|l|c|c|c|c|c|c|}
\hline \multicolumn{2}{|c|}{ Scale } & \multicolumn{2}{c|}{ GCS } & \multicolumn{2}{c|}{ APACHII } \\
TXA2 & Aspirin resistant & Aspirin sensitive & Aspirin resistant & \multicolumn{2}{c|}{ Aspirin sensitive } & \multicolumn{2}{c|}{ Aspirin resistant } & Aspirin sensitive \\
\hline $\mathrm{R}$ & -0.52 & 0.01 & 0.44 & -0.08 & -0.31 & -0.06 \\
\hline $\mathrm{P}$ & $<0.001 * *$ & $>0.05$ & $<0.001 * *$ & $>0.05$ & $>0.05$ & $>0.05$ \\
\hline
\end{tabular}

\section{Discussion}

Aspirin resistance was found to be present in 27 patients $(33.75 \%)$ out of the 80 surviving ischemic (non-cardioembolic) stroke patients during the week of the study. This is in accordance with Lev et al [8] and Ozben et al [9], while Laxami et al [10] stated that prevelance of aspirin resistance in their study was $23.7 \%$. This may be explained by different sample size, different types of population and different tests used to measure aspirin resistance [10].

The present study showed that there was no statistically significant difference between the two groups regarding age and sex and this is in accordance with Ozben et al [9] while El-Mitwalli et al [11] found that aspirin resistance was significantly higher in males and older age.

Regarding other risk factors of stroke as smoking, diabetes, hypertension, dyslipideamia, migraine, obesity, 
obstructive sleep apnea and contraceptive pills, there was no significant difference between the two groups in our study and this is in agreement with Santos et al [12] and El-Mitwalli et al [11]; On the other hand Zheng et al [13] in his study found that smoking was significantly higher in patients with aspirin resistance, this may be due to different sample size and different methodology in their study as they did not exclude cardioembolic strokes.

TIAs and previous stroke were more frequent in AR group and this is in agreement with Zheng et al. [13] and Laxami et al [10]. This was attributed to the potent action of TXA2 through stimulation of $G$ protein -coupled receptors on platelets leading to platelet aggregation and thrombus formation. TXA2 also has an essential pro-agreggative effects and promote other thrombotic mediators which may lead also to vasoconstriction [14]. These properties of TXA2 could be enhanced more by genetic polymorphism and changes of platelets receptors, COX1 gene mutation, overexpression of $\mathrm{COX} 2$, co-morbidity with diabetes, obesity, heart failure and accerelated platelet turn over [15].

On the contrary Ozben et al [9] and El-Mitwalli et al [11] found that previous stroke was not a significant factor aspirin resistance in their studies

In our study we found that history of TIAs was significantly higher in AR patients, this is in accordance Laxami et al [10]. This could be attributed to decrease in the response to aspirin that leads to inadequate reduction to platelet derived vasoconstricting products which may provoke ischemic attacks by affecting local blood flow [13].

We found also that dysphasia, motor power affection and sensory deficits were more frequent in AR patients. Meanwhile the degree of affection (as assessed by NIHSS) was more severe in the same group and the differences between both groups were statistically significant.This was in agreement with Zheng et al [13] and Hughes [16] who attributed this to the lack of the neuroprotective mechanisms of aspirin, non decrement of glutamate mediated exitotoxcity in AR patients that lead to more severe stroke symptoms [13].

Vomiting, disturbed consciousness and stroke severity were more in AR patients as indicated by GCS and NIHSS. This is in accordance with Ozben et al [9], Zheng et al [13], Oakes [17] and Oh et al [18], and it was explained by the result of inadequate inhibition of platelet activity and reduction of platelets microaggregates, the severity was also related to the deficiency of neuroprotective property and glutamate mediated excitotoxicity which resuled in large infarct size associated with more brain edema.

Shwammenthal et al [19] had another opinion as they stated in their study that AR patients were scored lower on NIHSS on admission, however large number of their patients in their cohort study were already on aspirin therapy prior to stroke onset by a long period of time.

El-Mitwalli et al [11] also had the same opinion that argued about the effect of AR on NIHSS and reported that there was no significant difference between the resistant and sensitive groups of patients.

On assessment of APACHE II (mortality predictor) in our patients we noticed that it predicted high significant mortality in AR patients and this might be due to the more severe insult and large size of cerebral infarct in this group.
This is in accordance with Ozben et al [9] who also noticed that aspirin resistance increased risk of mortality among population of ischemic stroke patients, both inhospital and in two years follow up, this was also noticed by Santos et al [12].

Concerning the size of cerebral infarct, it was found to be statistically significantly larger in AR group and there was positive correlation between this and TXA2 level. These findings are in agreement with Zheng et al [13], Oakes [17] and Oh et al [18]. They attributed this to the fact of inability to reduce carotid mural thrombi, platelets inhibition failure and platelets microaggregate Increase of neurotoxic substance and larger cerebral tissue ischemia may lead to prothrombotic inflammatory reaction and incomplete response to aspirin Zheng et al [13]. On the other hand, El-Mitwalli et al [11] and Taekim et al [20] reported that lacunar infarcts were more prevelant in AR patients as they did not exclude patients with atrial fibrillation.

In our observational study we noticed that parietal and temporal cerebral infarcts were significantly more frequent in AR patients, this is in accordance with Zheng et al [13], who also found that Total Anterior circulation infarctions were higher in aspirin resistant patients and explained this by deficiency of platelet inhibition with occlusion of large artery and formation of larger thrombus.

One week following stroke onset we noticed that there was significant negative correlation between TXA2 level and bleeding time in AS group, while there was no correlation between TXA2 and clotting time in both groups, this is explained by the effect of aspirin on TXA2 during hemostasis $\mathrm{TXA}_{2}$ is the main product that is formed, by the specific isomerase called $\mathrm{TXA}_{2}$ synthase, and it acts as a platelet agonist, vasoconstrictor, and vascular smooth muscle cell mitogen [21].

In our study we found that there was a highly significant negative correlation between GCS and TXA2 level and also a highly significant positive correlation between NIHSS and TXA2 level in AR patients, this could be explained by aspirin resistance defined by elevated TXA2 level was associated with more severe stroke. This was in agreement with Ozben et al [9], Zheng et al [13] and Oakes [17]. This was explained as follow: aspirin role was not effective enough resulting in inadequate inhibition of platelet activity and reduction of platelets microaggregates. The severity was also related to the defiiciency of neuroprotective property and glutamate mediated excitotoxicity.

There was also a highly significant positive correlation between TXA2 level and size of cerebral infarct, these findings are in agreement with Zheng et al [13], Oakes [17] and $\mathrm{Oh}$ et al [18]. They attributed this to the fact of inability to reduce carotid mural thrombi, platelets inhibition failure and platelets microaggregate. Increase of neurotoxic substance and larger cerebral tissue ischemia also may lead to prothrombotic inflammatory reaction and incomplete response to aspirin [13].

\section{Conclusion}

- AR was frequent among patients with acute ischemic stroke: TIAs and previous strokes were 
associated with high risk of stroke recurrence and this may be due to aspirin resistance.

- Aspirin resistance was associated in our study with more severe clinical presentation (detected by clinical examination, and by GCS, NIHSS and APACHII score, and by the presence of larger size of cerebral infarcts.

\section{Recommendations}

- Early detection of AR via recent \& rapid methods in acute ischemic stroke patients who will be treated conservatively is mandatory to guard against its useless treatment and to choose other options of treatment which can prevent progress of stroke and limit its severity and complications.

- The early detection of AR patients who suffered from an ischemic stroke or those who are vulnerable to develop it allow proper therapeutic strategies in primary or secondary prevention of ischemic stroke.

- Further studies will be needed to detect more data about AR \& if it is a real situation or just it is a failure of treatment due to presence of other factors which prevent its efficacy.

\section{References}

[1] Yip HK, Liov CW, Chang HW, Lan MY, Liv JS and Chen MC (2005): Link between platelet activity and outcomes after an ischeamic stroke. Cerebrovasc Dis; 20: 120-128.

[2] Stewart M, Knoepp and Michael Laposata (2005): Aspirin Resistance: Moving Forward With Multiple Definitions, Different Assays, and a clinical Imperative. Am J Clin Path; 123 (1): 125-13.

[3] Neki NS (2009): Aspirin resistance current issue. JIACM, 10(3): 134-139.

[4] Anetta Undas, Kathleen E, Brummel-Ziedins and Kenneth G. Man (2007): Antithrombotic properties of aspirin and resistance to aspirin: beyond strictly antiplatelet actions. Blood; 109 : 2285-2292.

[5] Okay Abaci, Kadriye Orta (2013): Aspirin resistance: where are we now? Anadolu Kardiyol Derg; 13: 370-373.

[6] Topcuoglo MA, Arsava EM and Hakan AG (2011): Antiplatelet resistance in stroke. Expert Rev Neurother; 11: 251-263.

[7] IBM Corp. realeased (2013): IBM SPSS Statistics for windows, Version 22.0 Armonk, NY: IBM Corp.

[8] Lev EI, Solodky A, Harel N, Mager A, Brash D, Assali A, Roller M, Battler A (2010): Treatment of aspirin resistance patients with omega-3 fatty acids versus aspirin dose escalation. J. Am. C. Card.; 55 (2): 114-121.

[9] Ozben S, Ozben B, Tannikula AM, OZer F, Ozben T (2011): Aspirin resistance in patients with acute ischemic stroke. J Neurol; 258: 1979-1986.

[10] Laxami SS, Virendra A, Rajesh V, Ashutosh K, Jyotsana S, Isha A (2015): Prevalence of aspirin resistance in patients with ischemic stroke at a tertiary care center in North India. JMSCR, 3 (3): 4684-6493.

[11] El-Mitwalli A, Azzam H, Abu-Hegazy M, Gomaa M, Wasel Y (2013): Clinical and biochemical aspirin resistance in patients with recurrent cerebral ishcmeia. J. Clin.Neurol. Neurosurg. 115: 9444-94.

[12] Santos MT, Valles J, Lago A, Tembl J, Sanchez E, Moscardo A, Cosin J (2008): Residual platelet thromboxan A2 and prothrombotic effects of erythrocytes are important determinants of aspirin resistance in patients with vascular disease. J Thromb Hemost; 6: 615-621.

[13] Zheng AS, Churilov L, Colley RE, Goh C, Davis SM, Yan B (2013): Association of aspirin resistance with increased stroke severity and infarct size. JAMA Neurol; 70 (2): 20-213.

[14] Knoepp, Stewart M, Laposata M (2005): Aspirin resistance: moving forward with multiple definitions, different assays, and a clinical imperative. Am J Clin Path; 123 (1): 125-132.

[15] Ahmmad F, Shamsunnahar (2013): Aspirin resistance and newer combatants against it. Farid pur Med Coll J; 8 (2): 92-95.

[16] Hughes S (2015): Asprin resistance linked to more severe strokes. Medscape Medical News. http://www.medscape.com/reviewarticle/840977

[17] Oakes K (2015): Larger and more severe strokes seen with aspirin resistance. Glob. Acad. M. Edu.; 19.

[18] Oh MS, Yu CH, Jung S, Kim C, Jang MU, Lee BC (2016): Aspirin resistance is associated with increased stroke severity and infarct volume. Neurology; 86 (9): 1808-1817.

[19] Schwammeenthal Y, Tsabri R, Shenkman B, Schwartz R, Matetzky S, Lubetsky A (2008): Aspirin responsiveness in acute brain ischemia: Association with stroke severity and clinical outcome. Cerebrovasc Dis; 25: 355-361.

[20] Taekim J, Heo S, Lee JS, Choi M, Choi KH, Nam TS, Lee SH, park MS, Kim BC, Kim MK, Cho KH (2015): Aspirin resistance in the acute stages of acute ischemic stroke is associated with the development of new ischemic lesions.

[21] Frishman WH, Lerner RG, Klein MD, Roganovic M (2003): Antiplatelet and antithrombotic drugs. In: Fr-ishman WH, Sonnenblick EH, Sica DA, eds. Cardiovascular Pharmaceutics. New York, NY: McGraw Hill: 259-299.

[22] Gum PA, Marchant K, Welch PA, White J, Topol E (2003): A prospective blinded determination of the natural history of aspirin resistance among stable patients with cardiovascular diseases. J Am CollCardiol; 41: 961-965.

[23] Sacco RL, Kasner SE, Broderick JP, Caplan LR, Connors JJ, Culebras A, Elkind MS, George MG, Hamdan AD, Higashida RT, Hoh BL, Janis LS, Kase CS,Kleindorfer DO, Lee JM, Moseley ME, Peterson ED, Turan TN, Valderrama AL (2013): An updated definition of stroke for the 21st century: a statement for healthcare professionals from the American Heart Association/American Stroke American. Stroke; 44 (7): 2064-2089. 